\title{
Proximal aortic stiffening in Turner patients may be present before dilation can be detected: a segmental functional MRI study
}

Daniel G. H. Devos ${ }^{1 *}$, Katya De Groote ${ }^{2}$, Danilo Babin ${ }^{3}$, Laurent Demulier ${ }^{4}$, Yves Taeymans $^{4}$, Jos J. Westenberg ${ }^{5}$, Luc Van Bortel ${ }^{6}$, Patrick Segers ${ }^{7}$, Eric Achten ${ }^{1}$, Jean De Schepper ${ }^{8}$ and Ernst Rietzschel ${ }^{4}$

\begin{abstract}
Background: To study segmental structural and functional aortic properties in Turner syndrome (TS) patients. Aortic abnormalities contribute to increased morbidity and mortality of women with Turner syndrome. Cardiovascular magnetic resonance (CMR) allows segmental study of aortic elastic properties.

Method: We performed Pulse Wave Velocity (PWV) and distensibility measurements using CMR of the thoracic and abdominal aorta in 55 TS-patients, aged 13-59y, and in a control population ( $n=38 ; 12-58 y)$. We investigated the contribution of TS on aortic stiffness in our entire cohort, in bicuspid (BAV) versus tricuspid (TAV) aortic valvemorphology subgroups, and in the younger and older subgroups.

Results: Differences in aortic properties were only seen at the most proximal aortic level. BAV Turner patients had significantly higher PWV, compared to TAV Turner $(p=0.014)$, who in turn had significantly higher PWV compared to controls $(p=0.010)$. BAV Turner patients had significantly larger ascending aortic (AA) luminal area and lower AA distensibility compared to both controls (all $p<0.01$ ) and TAV Turner patients. TAV Turner had similar AA luminal areas and AA distensibility compared to Controls. Functional changes are present in younger and older Turner subjects, whereas ascending aortic dilation is prominent in older Turner patients. Clinically relevant dilatation (TAV and BAV) was associated with reduced distensibility.

Conclusion: Aortic stiffening and dilation in TS affects the proximal aorta, and is more pronounced, although not exclusively, in BAV TS patients.

Functional abnormalities are present at an early age, suggesting an aortic wall disease inherent to the TS. Whether this increased stiffness at young age can predict later dilatation needs to be studied longitudinally.
\end{abstract}

\section{Background}

Turner syndrome (TS), occurring in approximately one in 2500 live born girls [1], is associated with left sided congenital cardiovascular defects. A bicuspid aortic valve (BAV) is found in up to one third of TS patients [2]. Aortic arch abnormalities such as a dysmorphic aorta or coarctation can be found in up to $50 \%$ of the patients [3-5]. Turner patients have increased risk of

\footnotetext{
*Correspondence: daniel.devos@uzgent.be

'Department of Radiology, MRI (-1K12), Ghent University Hospital, De

Pintelaan 185, B-9000 Gent, Belgium

Full list of author information is available at the end of the article
}

acquired aortic disease such as progressive dilation of the ascending aorta and dissection [2, 4, 6-11]. These aortic abnormalities contribute to the increased cardiovascular morbidity and mortality of women with Turner syndrome $[4,6,12,13]$. Aortic dissection is a wellknown fatal complication in TS patients and often occurs at a much younger age than in the general population. Detection of the patient at increased risk is difficult. The presence of a BAV, coarctation of a dilated aorta, as well as hypertension heralds higher risk, and warrants closer follow up [14]. But regardless of the presence of risk factors, follow up of aortic diameters 
has been inadequate at reliably predicting cardiovascular risk [15].

Besides excellent morphologic imaging, cardiovascular magnetic resonance (CMR) also allows assessment of segmental functional elastic properties of the aorta. Loss of aortic elasticity of the proximal aorta increases the left ventricle's afterload and is related to increased cardiovascular risk [16]. In the older population as well as in several disease states, arterial stiffness has been shown to increase with age and to contribute to the pathogenesis of systolic hypertension and cardiovascular disease (end stage renal disease, hypertension, and coronary artery disease) [17-22].

Although numerous invasive and non-invasive descriptors of aortic elastic properties have been described, most outcome data center on aortic pulse wave velocity (PWV) [23] and distensibility [20, 22, 24, 25]. Previously we have shown that age-associated loss of elasticity is more pronounced in the thoracic aorta compared to the abdominal aorta in healthy controls [26]. We now hypothesized that Turner syndrome is associated with proximal aortic stiffening, and investigated the influence of age on this stiffness increase. To our knowledge, this study is the first to investigate segmental aortic properties in Turner patients by means of CMR.

\section{Methods}

\section{Patient population}

Fifty-five consecutive female Turner patients, aged between 13 and 59 years, referred for routine morphologic CMR of the aorta, were prospectively included. Pregnant or lactating women, patients with pacemakers or implantable cardioverter defibrillators (ICD's), aneurysm clips, cochlear implants, neural stimulators, epileptic seizures, large tattoos, significant claustrophobia or morbid obesity that would not enable the subject to fit in the scanner, were excluded from the study. Patients who had had aortic valve replacement or arch stenting/surgery were excluded. The control group consisted of 38 apparently normal female subjects, aged between 12 and 58 year, recruited for a previous study on aortic PWV [26]. MR studies in all patients and controls were performed at the Ghent University Hospital, Belgium and reviewed by a single radiologist with 10 years of experience in cardiovascular CMR (DGHD). Body height and weight were measured prior to the MR examination. BMI and BSA, using the formula of weight divided by body height squared $(\mathrm{kg} /$ $\mathrm{m}^{2}$ ) and Mosteller [27] respectively, were calculated. We consulted the treating physicians and reviewed the patient medical records for documentation of estrogen replacement therapy (ERT). The study protocol was reviewed and approved by the Ghent University ethics committee. All patients and controls gave a written informed consent.

\section{MR scan protocol}

All patients and controls were scanned on a $1.5 \mathrm{~T}$ magnet (Siemens, Erlangen). The scan protocol consisted of HASTE images of the thorax and abdomen (TR: $800 \mathrm{~ms}$ TE: $28 \mathrm{~ms}$, FA: $160^{\circ} \mathrm{ST}: 6 \mathrm{~mm}$ ). On four locations along the aorta, a retrospectively ECG-gated gradient-echo sequence with velocity encoding perpendicular to the aorta was applied to measure throughplane flow velocity (TR: $73 \mathrm{~ms}$, TE: $4 \mathrm{~ms}$, FA: $30^{\circ}$, ST: $6 \mathrm{~mm}$, velocity sensitivity VENC: $150 \mathrm{~cm} / \mathrm{s}$, reconstructed phases: 40): ascending and descending aorta at the level of the pulmonary trunk were imaged in one series except in case of an extremely tortuous aorta, where two separate image planes were used; another series was placed at the level of the diaphragm, and a most distal series just above the aortic bifurcation [16]. A balanced fast field echo cine series with equal pixel matrix was acquired in exactly the same orientation (TR: $26-30 \mathrm{~ms}$, TE: $1.2-1.5 \mathrm{~ms}$, FA: $65-80$, ST: $6 \mathrm{~mm}$, number of images per cardiac interval: 40). During this breath hold, blood pressure was measured with a non invasive blood pressure monitor, using an adapted to size blood pressure cuff around the left upper arm (Tesla NIBP, Mammendorf, Germany). Baseline blood pressure was the average of all measurements that were performed during transverse scans.

In addition a standard keyhole high temporal, high spatial resolution MRA sequence of the entire aorta (Isovolumetric $(1.3 \mathrm{~mm})$ matrix $240 \times 320$ pixels, FOV: 420x320mm, TR: $2.6 \mathrm{~ms}$, TE: $0.9 \mathrm{~ms}$, symmetrically shared 33\% peripheral K-space data for 20\% central data (TWIST, time-resolved angiography with stochastic trajectories) was performed in patients. Aortic arch morphology was classified as normal arch (Romanesque, no stenosis and no arteria subclavia lusoria) or elongated transverse arch, tortuous arch, crenel shaped arch or gothic arch [4].

\section{Postprocessing}

Postprocessing was performed off-line by a single radiologist (DGHD). It consisted first of manually drawing a centerline in the aortic lumen on a parasagittal angiographic planar reformatted image (so called candy cane view of the aorta). Along this centerline, the distance $(\Delta \mathrm{x})$ was measured between the positions where the Phase Contrast images of the ascending aorta, the aorta at diaphragmatic level, and just above the aortic bifurcation were made (Additional file 1: Figure S1). On these phase contrast images the aortic lumen was segmented in an automated fashion [28]. Using in-house developed MATLAB code, the last 5 data points of each flow-time curve were cut and pasted in front of the time series, in order to translate the curve in time, ensuring that the onset of each curve was positioned after the start of the 
revised time series (Additional file 2: Figure S2). The graphs were subsequently processed in a custom-made PWV analysis tool as described by Grotenhuis et al. [29]: the onset of the systolic wave front was automatically determined from the resulting flow graph by the intersection point of the constant horizontal diastolic flow and the upslope of the systolic wave front, the latter of which was modeled by linear regression along the upslope from the flow values between $20 \%$ and $80 \%$ of the total range (Additional file 3: Figure S3). PWV was calculated as the ratio of distance $\Delta \mathrm{x}$ per time $\Delta \mathrm{t}$, where $\Delta \mathrm{x}$ is the length of an aortic segment (thoracic, abdominal or entire aorta, see Additional file 1: Figure S1) measured on the MR image data along the centerline, and $\Delta t$ is the time duration needed for the pulse wave velocity to travel that length through the aorta.

Maximum and minimum transverse aortic luminal areas were manually located and drawn on the cine series. Distensibility was calculated as:

$$
\mathrm{D}=(\operatorname{Amax}-\mathrm{Amin}) /(\operatorname{Amin} *(\operatorname{Pmax}-\mathrm{Pmin}))
$$

where Amax and Amin are maximum and minimum area, Pmax is peak systolic blood pressure and Pmin is minimal (diastolic) blood pressure; it is expressed as $1 /$ 1000* $\mathrm{mmHg}$. These blood pressures were taken from left arm sphygmomanometric measurement during the actual distensibility scan.

\section{Statistical analysis}

Statistical exploration was performed in Wizard v1.8.9 (OSX El Capitan v10.11.4).

Statistical analysis was performed in SPSS for Windows (version 22; SPSS, Chicago, Illinois, USA). Normality of distribution was explored with histograms and $\mathrm{Q}-\mathrm{Q}$ plots. Baseline data are expressed as mean (standard deviation; SD) and compared with an independent T-test if normally distributed. PWV values were expressed as median (interquartile range) and compared using the Kruskal Wallis test. For the multivariate analyses General Linear Modeling was used adjusting for age, height, weight, heart rate and systolic blood pressure as covariates. The dependent variables in these models were $\ln$-transformed PWV, distensibility and area values because of some skewness towards higher values. The level of significance was set at $p<0.05$.

\section{Results}

\section{Population characteristics}

Clinical characteristics and cardiac parameters of both the control and Turner population are listed in Table 1. The Turner population was significantly shorter, and had a higher BMI compared to controls. Haemodynamically, TS patients had a similar mean systolic blood pressure
Table 1 Population characteristics

\begin{tabular}{|c|c|c|c|}
\hline & $\begin{array}{l}\text { Control } \\
(n=38)\end{array}$ & $\begin{array}{l}\text { Turner } \\
(n=55)\end{array}$ & $p$ value \\
\hline Age (y) & $34(14)$ & $29(11)$ & 0.060 \\
\hline Length (cm) & $166(8)$ & $154(7)$ & $<0.001$ \\
\hline Weight (kg) & $61(11)$ & $57(11)$ & 0.159 \\
\hline BMI $\left(\mathrm{kg} / \mathrm{m}^{2}\right)$ & $21.8(3.1)$ & $24.3(4.3)$ & 0.003 \\
\hline BSA (Mosteller) & $1.67(.17)$ & $1.56(0.17)$ & 0.003 \\
\hline Systolic BP (mmHg) & $118(14)$ & $121(16)$ & 0.259 \\
\hline Diastolic BP (mmHg) & $70(9)$ & $81(12)$ & $<0.001$ \\
\hline Heart Rate (bpm) & $69(10)$ & $79(13)$ & $<0.001$ \\
\hline Bicuspid aortic valve (\%) & $0 \%$ & $16 \%$ & \\
\hline Aortic arch length (mm) & $97(13)$ & $102(20)$ & 0.158 \\
\hline Descending aorta (mm) & $108(15)$ & $100(13)$ & 0.008 \\
\hline Abdominal aorta (mm) & $170(21)$ & $158(20)$ & 0.007 \\
\hline Thoracic aortic PWV (m/s) ${ }^{a}$ & $3.7(1.7)$ & $4.4(1.7)$ & 0.127 \\
\hline Abdominal aortic PWV (m/s) ${ }^{a}$ & $4.7(2.5)$ & $4.8(1.6)$ & 0.829 \\
\hline Overall aortic PWV (m/s) ${ }^{a}$ & $4.1(1.6)$ & $4.4(1.2)$ & 0.23 \\
\hline
\end{tabular}

Values are Mean (standard deviation), comparison using unpaired t-test. All variables normally distributed, except PWV values $\left({ }^{\mathrm{a}}\right)$ which are expressed as median (interquartile range), comparison using the Kruskal-Wallis test. Bold indicates $<0.05$

compared to controls, but presented with a higher mean heart rate and diastolic blood pressure. Mean left ventricular volume including stroke volume was smaller in TS patients, even after normalization for Body Surface Area (BSA). There was no significant difference in mean left ventricular ejection fraction, nor in left ventricular mass normalized for body surface area. As expected, TS patients, being smaller, had significantly shorter descending thoracic aorta and abdominal aortic lengths. In contrast, their aortic arch length was similar to the controls'. While all controls had tricuspid aortic valves, 16 Turner patients had a bicuspid aortic valve (BAV).

\section{Comparison of aortic measurements in Turner patients and in controls}

The multivariate determinants of aortic wall properties were assessed in a Generalized Linear Model (GLM) including the presence of Turner syndrome and adjusting for possible confounders: age, height, weight, heart rate and systolic blood pressure. Age was included as a covariate to take into account the potential effect of the non-significant age difference between Turners and controls.

The effect of the presence or absence of Turner syndrome is shown in Fig. 1 where estimated marginal means were plotted for thoracic, abdominal and total aortic PWV, area and distensibility in Turner patients versus controls. As expected in all models, age was the strongest determinant. Turner patients had significantly 


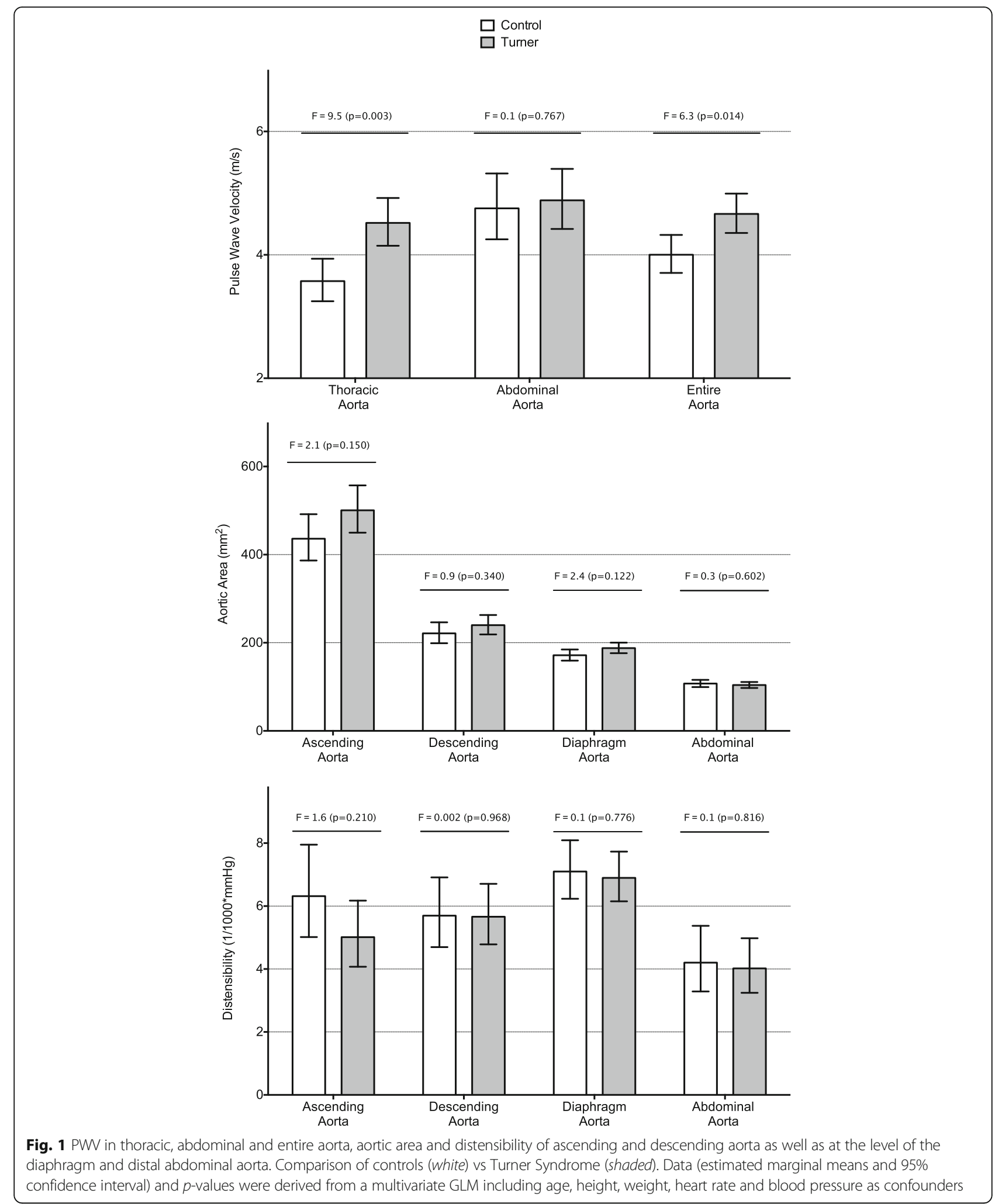

higher thoracic aortic PWV (TA-PWV) compared to controls. Abdominal PWV was similar, the higher overall aortic PWV in Turner subjects being driven by the higher
TA-PWV. No statistically significant differences in aortic area and distensibility were seen between Turner patients and controls. 


\section{The impact of aortic valve morphology on aortic parameters}

We then analysed the impact of aortic valve morphology. Table 2 shows the baseline characteristics of the BAV Turner patients, Tricuspid Aortic Valve (TAV) Turner patients, and controls. There were no significant differences between baseline population characteristics of TAV and BAV Turner patients.

To assess the effect of aortic valve on the aortic properties, we performed a GLM analysis comparing controls, TAV Turner and BAV Turner, again adjusting for age, height, weight, heart rate and systolic blood pressure. The results are plotted in Fig. 2, showing the multivariate adjusted estimated marginal means (and 95\% confidence interval) of the studied aortic parameters. Overall, differences in aortic properties were seen at the most proximal aortic level: BAV Turner patients had significantly higher PWV, compared to TAV Turner $(p=0.014)$, who in turn had significantly higher PWV compared to controls $(p=0.010)$. BAV Turner patients had significantly larger AA luminal area and lower AA distensibility compared to both controls (all $p<0.01)$ and TAV Turner patients. TAV Turner had similar ascending aortic luminal areas and ascending aortic distensibility compared to Controls.

No consistent differences were seen across groups in more distal aortic characteristics. Exceptions were marginal (but significant) differences in diaphragmatic area (larger in BAV Turner patients), and differences in overall aortic PWV (Turner higher than controls), again driven by the differences in thoracic PWV, as abdominal PWV values were similar.

Adding left ventricular stroke volume, which was significantly smaller in Turners compared to controls, to these models did not substantially change the results (data not shown).
The impact of age on aortic parameters

We plotted F and $p$ values of the used GLM model within the Turner group and the control group separately in Additional file 4: Table S1. Age is the main determinant of PWV, aortic luminal area and distensibility at all levels in both groups, only surpassed slightly by systolic blood pressure for descending and distal abdominal distensibility in Turner patients (and weight for distal abdominal aortic area in the control group).

Using the same model separately in the TAV Control group, in the TAV Turner patient group and in the BAV Turner patient group ( $\mathrm{F}$ and $p$ values in Additional file 5: Table S2), the independent association between aortic properties and age remain largely unchanged in both TAV groups. Strikingly, in BAV Turners almost all effects of age, blood pressure, height and weight were lost.

To further study whether the impact of Turner Syndrome on aortic properties is different in younger versus older subjects, we divided all three subgroups into two halves, above and below their respective median age. Age cut-offs were 27 years for TAV Turner subjects; 23.5 years for BAV Turner subjects; 32 years for Controls. A similar GLM model adjusting for age, height, weight, heart rate and systolic blood pressure was used and the results of proximal aortic properties are shown in Fig. 3. Overall, the functional changes (borderline increase in thoracic PWV and significant loss of proximal aortic distensibility) are present in both younger and older Turner subjects, whereas structural remodeling (enlargement of ascending aortic) clearly is only prominent in older BAV Turners.

Finally, we plotted the ascending aortic area in relation to the ascending aortic distensibility for young and old groups of controls, TAV and BAV Turner patients (Fig. 4). This graph illustrates the inverse correlation between

Table 2 Subgroup characteristics and comparison

\begin{tabular}{|c|c|c|c|c|c|c|}
\hline & $\begin{array}{l}\text { TAV Control } \\
(n=38)\end{array}$ & $\begin{array}{l}\text { TAV Turner } \\
(n=39)\end{array}$ & $\begin{array}{l}\text { BAV Turner } \\
(n=16)\end{array}$ & $\begin{array}{l}\text { Control-TAV Turner } \\
p\end{array}$ & $\begin{array}{l}\text { Control-BAV Turner } \\
p\end{array}$ & $\begin{array}{l}\text { TAV- BAV Turner } \\
p\end{array}$ \\
\hline Age (y) & $34(14)$ & $30(12)$ & $25(9)$ & 0.241 & 0.008 & 0.128 \\
\hline Length (cm) & $166(8)$ & $154(8)$ & $152(6)$ & 0.000 & 0.000 & 0.466 \\
\hline Weight (kg) & $61(11)$ & $58(12)$ & $55(8)$ & 0.329 & 0.099 & 0.458 \\
\hline Heart Rate (bpm) & $69(10)$ & $78(14)$ & $83(8)$ & 0.002 & 0.000 & 0.120 \\
\hline $\mathrm{BMI}\left(\mathrm{kg} / \mathrm{m}^{2}\right)$ & $21.8(3.1)$ & $24.4(4.8)$ & $23.9(2.8)$ & 0.006 & 0.032 & 0.589 \\
\hline BSA (mosteller) & $1.67(0.17)$ & $1.6(0.2)$ & $1.5(0.1)$ & 0.016 & 0.007 & 0.454 \\
\hline Systolic BP (mmHg) & $118(14)$ & $123(16)$ & $118(14)$ & 0.151 & 0.982 & 0.316 \\
\hline Diastolic BP (mmHg) & $70(9)$ & $82(14)$ & $80(9)$ & 0.000 & 0.002 & 0.528 \\
\hline Aortic arch length (mm) & $97(13)$ & $99(15)$ & $110(27)$ & 0.542 & 0.021 & 0.055 \\
\hline Descending aorta (mm) & $108(15)$ & $102(13)$ & $96(12)$ & 0.050 & 0.009 & 0.159 \\
\hline Abdominal aorta (mm) & $170(21)$ & $156(21)$ & $163(16)$ & 0.005 & 0.235 & 0.245 \\
\hline
\end{tabular}

Descriptive parameters per subgroup, with $p$-value (t-test; bold indicates $<0.05$ ) for each comparison of two subgroups 


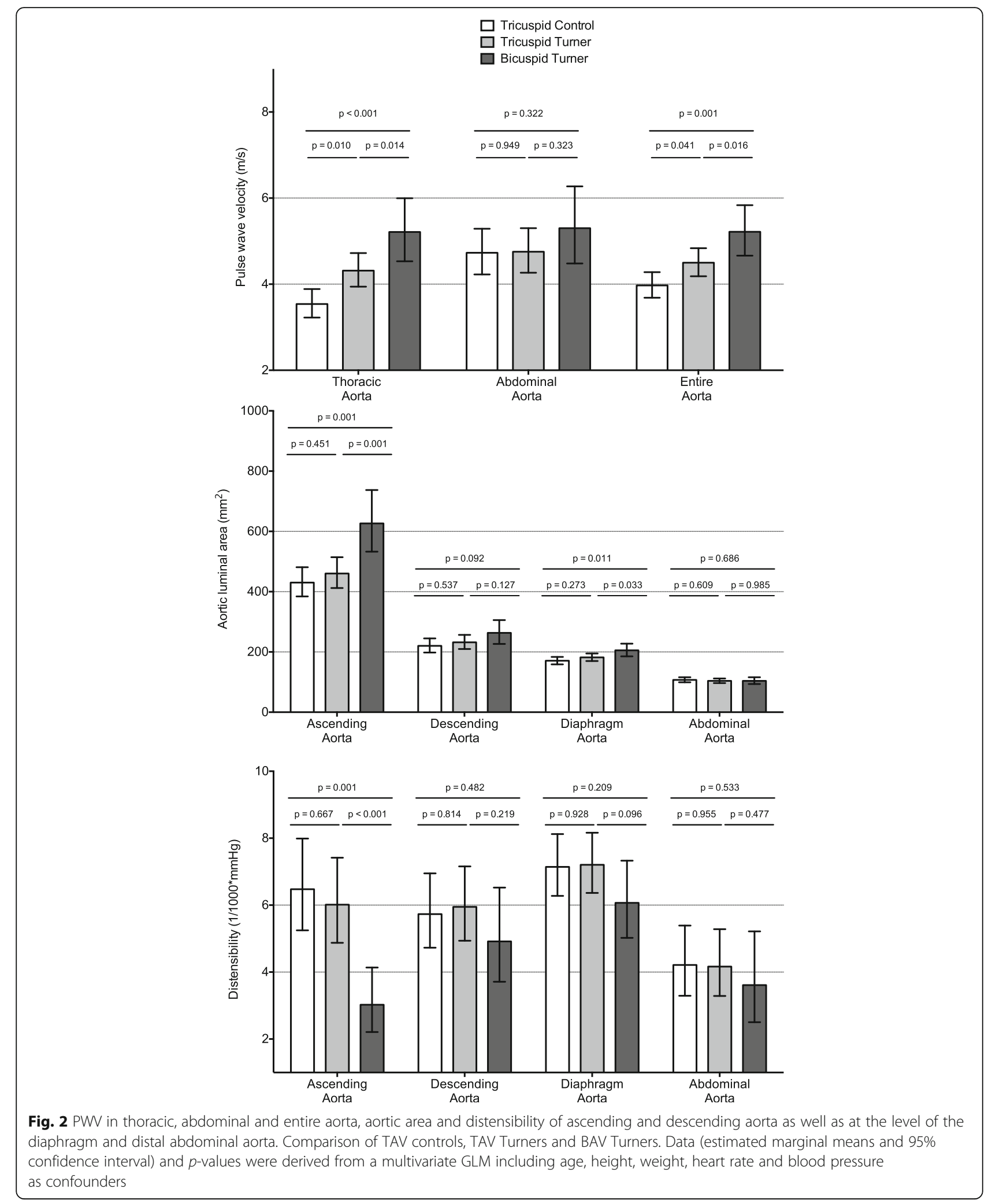

ascending aortic area (BSA-normalised) and its distensibility (incremented and ln-transformed), or, larger aortas are stiffer in older controls and Turner patients $(p<0.001)$, regardless of aortic morphology. There is no such correlation in the younger subjects (either controls or Turner patients). 

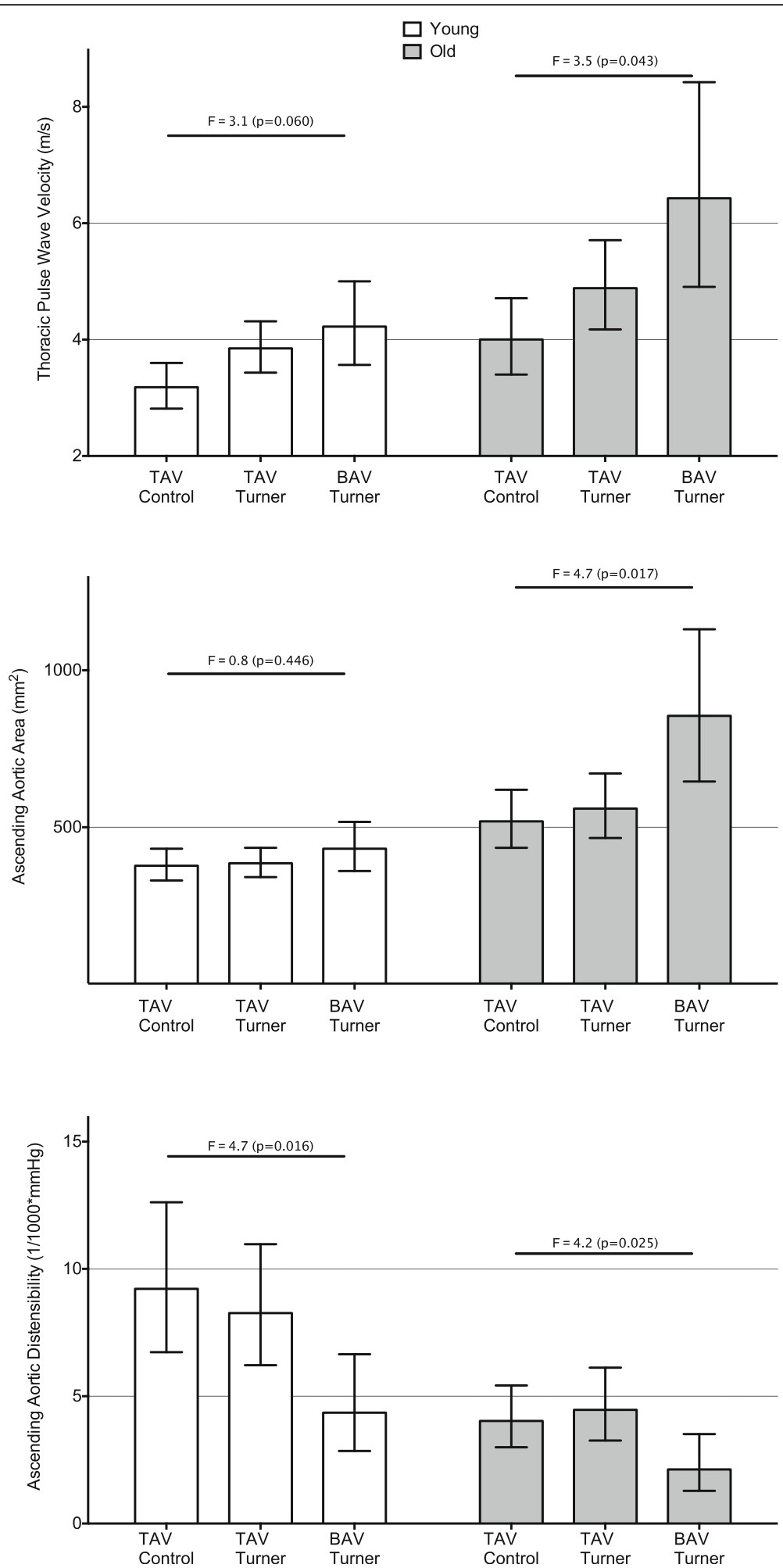

Fig. 3 Thoracic PWV, ascending aortic area and distensibility. Comparison younger half (white) vs older half (shaded) in TAV control group, TAV Turner group and BAV Turner group. Data (estimated marginal means and 95\% confidence interval) and $p$-values were derived from a multivariate GLM including age, height, weight, heart rate and blood pressure as confounders 

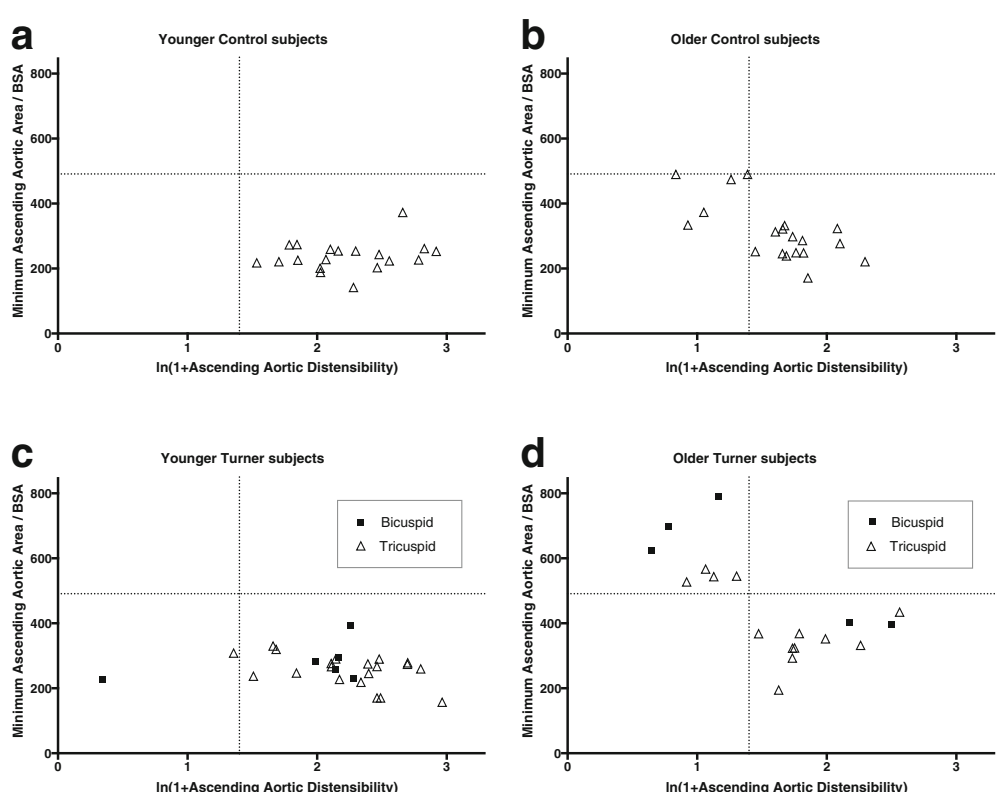

Fig. 4 Scatterplots of ascending aortic area (BSA-normalised) and distensibility (incremented and In-transformed) in young (a) and old (b) Controls and in young (c) and old (d) Turner patients, illustrating an inverse relation in the older half of both populations, irrespective of aortic valve morphology (triangle $=$ tricuspid valve; square $=$ bicuspid valve). The reference line at a normalised ascending aortic area of $491 \mathrm{~mm} / \mathrm{m}^{2}$ corresponds to the cut-off aortic diameter of $2.5 \mathrm{~cm} / \mathrm{m}^{2}$

\section{Additional results}

We found ERT in at least 43 of 55 Turner patients (78\%). Four patients previously received ERT, but it was stopped or temporarily interrupted in the year of the MR scan. Retrospectively, we could not rule out that the remaining 8 patients ever had been on ERT (5 Turner patients probably not on ERT, and unknown in 3).

Aortic arch morphology was normal (Romanesque, no stenosis, no lusoric subclavian artery) in all 38 control subjects, compared to only 20 out of 55 Turner patients. Thirty-five Turner patients had aortic arch abnormalities: 21 elongated transverse arches, 5 tortuous arches, 4 crenel shaped arches, 2 gothic arches, 6 subjects had an aortic arch stenosis (5/6 were moderate stenosis), and 8 subjects had an arteria subclavia lusoria. Adding aortic arch abnormalities to the GLM models did not impact the models for PWV, but for AA distensibility and for AA area, the aortic arch abnormalities competed with the diagnosis of Turner Syndrome and/or presence of a bicuspid aortic valve (i.e. partial co-linearity, especially with BAV presence).

\section{Discussion}

In this study, we evaluated PWV, luminal area and distensibility of both the thoracic and abdominal aortic segments in 55 Turner patients compared to controls. The main findings of our study are that (i) only the proximal aorta is significantly stiffer (PWV) in Turner patients compared to controls, independently of body height, (ii) the ascending aorta is significantly less distensible and also more enlarged in Turner patients with a bicuspid aortic valve compared to Turner patients with a tricuspid aortic valve, and (iii) the functional proximal aortic changes were largely similar when comparing younger and older TS patients, but aortic dilatation (more pronounced in BAV Turner patients) seems acquired/progressive, although this interpretation should be seen as purely hypothesis-generating due to the cross-sectional nature of our data. Those subjects with clinically relevant dilatation $\left(>2,5 \mathrm{~cm} / \mathrm{m}^{2}\right)$ had a markedly reduced distensiblity. The scatterplot between AA area/BSA and distensibility shows a distinct (almost bimodal) distribution with dilated and stiff AA clearly clustering compared to non-dilated and less stiff AA.

Our data supports the previously reported dilation of the proximal segment of the aorta in Turner syndrome $[28,30-32]$. Matura et al. found that $24 \%$ of TS patients had dilatation of the ascending aorta defined as exceeding the 95th percentile of BSA-adjusted aortic diameter for age-matched control women, and they proposed that this group required close cardiological surveillance. Within this cohort of dilated ascending aorta in TS, they identified a population of TS at highest risk for dissection with a cut-off of BSA-adjusted aortic diameter $>2.5 \mathrm{~cm} / \mathrm{m}^{2}$ or an absolute diameter $>3.5 \mathrm{~cm}$ [28]. Extrapolating from these cut-offs we calculated that a BSA-adjusted aortic diameter $>2.5 \mathrm{~cm} / \mathrm{m}^{2}$ would equate a BSA-adjusted area of $>4,91 \mathrm{~cm}^{2} / \mathrm{m}^{2}$. This cut-off was 
exceeded in our cohort by $11.4 \%$ of TAV Turner patients, $26,7 \%$ of BAV Turner patients, and none of the controls (Chi-square test; $p=0.008$ ). It is noteworthy that those Turner subjects with dilated ascending aortas were characterized by a clearly lower ascending aortic distensibility (see Fig. 4). In 2011, Mortensen reported that the ascending aorta in TS is diseased and dilated, and that the proximal aortic diameter growth rate was $0.1-0.4 \mathrm{~mm} /$ year; presence of a BAV was associated with a significantly increased growth rate [30].

Whilst it has been reported -using various methodologies- that Turner patients have a stiffer aorta compared to controls [33-35], this is the first study using CMR PWV to assess the functional properties of the aorta at various aortic levels. Indeed, we confirm the previous findings that Turner subjects have stiffer arteries, but extend this by documenting a preferential involvement of the proximal aorta, especially in patients with a bicuspid aortic valve. In addition, BAV Turner patients had a (borderline) non-significantly longer aortic arch compared to TAV Turner patients. An elongated mid arch segment or more serious deformations of the entire arch [36] have been reported in these patients. It could be that a more precise way of quantifying aortic arch length and deformation allows for better differentiation of abnormality, and the relative impact on PWV of both aortic arch morphology and aortic wall stiffness in Turner syndrome.

In the younger half of our study subjects we found a significantly lower ascending aortic distensibility and borderline non-significant higher PWV of the thoracic aorta in BAV Turner patients, but no significant difference in ascending aortic transverse area. In the older half of our study population, we found significantly increased thoracic aortic PWV and ascending aortic area, as well as significantly decreased ascending aortic distensibility. However, correlation of ascending aortic area and distensibility shows that the presence of a bicuspid valve cannot on its own predict dilatation of the ascending aorta. As aortic wall stiffness seems increased at early age, before dilatation is detectable, we put forward the idea to study the possible prediction of proximal aortic dilatation from early distensibility measurements in further longitudinal studies.

The association of Turner syndrome with aortic wall disease presenting from young age, as we found in our data, is consistent with reports that increased risk of acute aortic dissection is present from as early as the second decade of life $[1,12,13]$, and that dissection may occur as early as the first decade of life [37]. Gravholt et al. have estimated the incidence of dissection of 36 per 100,000 Turner's syndrome years, compared with an incidence of 6 per 100,000 in the general population [38]. Meszaros found an incidence of dissection of 2.9/
100,000 patient years in a population study of 100,000 patients during 27 years in the hospitals of three adjacent small towns in western Hungary [39]. Turner patients are at risk of aortic dissection at a significantly younger age (31-35 years) [38, 40] than the normal female population (68 years) [41]. An et al. have reported recently that the aortic arch, measured by ultrasound, was not dilated but less elastic in 25 adolescent Turner patients compared to controls [42].

Our data support the closer follow up of those TS patients with a bicuspid aortic valve [7].

Which TAV Turner patients should be followed up equally frequently, all or only a subset with stiffer aorta at young age remains to be studied.

Whether TAV Turner patients can be followed up safely with less frequent re-examinations needs to be further studied. Current guidelines recommmend 'full evaluation with thoracic CMR at an age when it can be performed without sedation' in young Turner patients [43]. A practical approach could be to initially use ultrasound, and refer to CMR if the aorta cannot adequately be measured, and perform CMR at the age of 10 years; further follow up is currently guided by BSA normalized aortic diameters and the presence of risk factors [44].

\section{Study limitations}

A limitation of our study is the small number of patients, especially when groups were divided in subgroups: the total number of bicuspid Turner patients was only 16 . In addition the effect of estrogen replacement therapy (ERT) and previous growth hormone therapy was not studied. We did review the patient files for history of ERT, but with the vast majority of Turner patients on ERT, we were not able to divide into ERT/No ERT groups of sufficient size. However, the effect of ERT on aortic diameter was not statistically significant $(p=0.08)$ in a prospective 5 year follow up study $(n=78)$ [15]. In a smaller study the same group has investigated the effect of 6 months of ERT on ambulatory arterial stiffness index (AASI) derived from 24-hour ambulatory blood pressure: although Turner patients were found to have higher AASI when compared to controls, AASI was unchanged by ERT [45].

The age difference between control population and the 5 years younger Turner population was not significant, but once subdivided in valve morphology groups, the small BAV Turner patients were significantly younger than the TAV Turner patients. The older/younger subdivision of our control and Turner patients at the respective median line was chosen to preserve equal number of subjects in both young and old groups. Subdivision at one fixed age for all groups would hinder proper statistical analysis, as this would lead to comparing a large group of young Turner patients, with a small group of young controls. 
Blood pressure measurement was performed during the actual distensibility scan, but we were limited to a left arm sphygmomanometric measurement. This may not be representative for the blood pressure in the ascending aorta proximal to a dysmorphic arch.

The postprocessing of PWV is another limitation. Detection of the foot of the curve is difficult in such a fast physiologic process, when performed with the relatively poor temporal resolution of MR. However this limitation applies equally to all studied groups in this study. Our data did not allow analyzing smaller aortic segments. Other studies have focused on increasing temporal resolution by acquiring in-plane velocity encoded images [46, 47]. At the time our data acquisition started, transverse images and detection of the foot-of-the-curve time shift was the major proposed method, a transittime method focussing at the early systolic part of the curve in an attempt to avoid the effect of wave reflection, which, especially in a stiffer aorta, is important. It was used as early as 1993 by Mohiaddin et al. [48] and more recently, by means of computer phantoms, Dorniak et al. calculated the minimal required temporal resolution of $30 \mathrm{~ms}$ (35 image frames at a heartrate of $60 \mathrm{bpm}$ ) for accurate and precise quantitative flow data for CMR-PWV over the range $2-20 \mathrm{~m} / \mathrm{s}$ in the thoracic aorta [49]. Newer methods involve complex wavelet cross spectrum analysis [50], which equally have the advantage of being robust at lower temporal resolution.

Our transverse aortic area measurements were not corrected for longitudinal strain, which in the ascending aorta reduces systolic dilation and thus leads to underestimation of distensibility [51]. However, ascending and descending aortic distensibilities in our study are comparable. To minimize through-plane motion error, the ascending aortic cine image was positioned carefully out of range of the motion of the sinotubular junction. The reported perpendicular aortic areas in our work are enddiastolic. As for comparison with other PWV values in literature, it is important to note that the most critical aspect of PWV postprocessing is the lack of standardization and all-in-one software solutions.

Our data is not longitudinal. We can therefore not make assumptions regarding the evolution of a stiffer proximal aorta at young age towards dilatation at older age. We do however think this should be studied further.

\section{Conclusion}

In conclusion, Turner patients exhibit a predominantly proximal aortic stiffening and dilatation, especially -but not exclusively- if their aortic valve is bicuspid. Aortic stiffening in Turner syndrome is already present at an early age, whereas ascending aortic dilatation is not. We put forward the hypothesis that proximal aortic stiffness at early age may predict aortic dilatation in both bicuspid and tricuspid aortic valve Turner patients. This hypothesis should be studied longitudinally.

\section{Novelty and significance \\ What is new?}

We have studied segmental thoracic versus abdominal aortic Pulse Wave Velocity acquired with CMR in Turner patients.

\section{What is relevant?}

In Turner patients, structural (dilatation) and functional aortic wall changes (stiffening and loss of distensibility) are restricted to the proximal aorta, even more so -but not exclusively- in the presence of a bicuspid aortic valve.

Increased thoracic aortic wall stiffness is already present at a young age whereas the aortic dilatation was only seen in our older Turner patients, specifically in those with the most pronounced stiffening.

If proximal aortic stiffness measurements could be used to predict dilatation -and by extension, risk of dissection- at older age, the follow-up criteria and timing of both bicuspid and tricuspid aortic valve Turner patients could be redefined.

\section{Summary}

Turner patients exhibit a predominantly proximal aortic stiffening and dilatation, especially -but not exclusively- if their aortic valve is bicuspid. Aortic stiffening in Turner syndrome is already present at an early age, whereas ascending aortic dilatation is not. We put forward the hypothesis that proximal aortic stiffness at early age may predict aortic dilatation in both bicuspid and tricuspid aortic valve Turner patients. This hypothesis should be studied longitudinally.

\section{Additional files}

Additional file 1: Figure S1. Distance measurement along the aortic path. Aortic segment and abdominal segment length are measured. (PDF $166 \mathrm{~kb}$ )

Additional file 2: Figure S2. Transposition of 5 last curve data points to the left so as to view and analyze the foot of the curve. (PDF $69 \mathrm{~kb}$ )

Additional file 3: Figure S3. Determination of time interval between velocity curves based on each curve's intersection point of the constant horizontal diastolic flow and the upslope of the systolic wave front. (PDF $69.5 \mathrm{~kb}$ )

Additional file 4: Table S1. Supplemental Table S1 A and B. F and $p$ values of PW, aortic area and aortic distensibility in amultivariate GLM including age, height, weight, heart rate and blood pressure as confounders, performedseperately within each of both groups: Turner patients (S1A) and controls (S1B). (XLSX $17 \mathrm{~kb}$ )

Additional file 5: Table S2. Supplemental Table S2 A, B and C. F and $p$ values of PW, aortic area and aortic distensibility in a multivariate GLM including age, height, weight, heart rate and blood pressure as confounders, performed seperately within each of three groups: TAV controls (S2A), TAV Turner patients (S2B) and BAV Turner patients (S2C). (XLSX $17 \mathrm{~kb})$ 


\section{Abbreviations}

AA: Ascending aorta; AASI: Ambulatory arterial stiffness index; BAV: Bicuspid aortic valve; BMl: Body mass index; BP: Blood pressure; BSA: Body surface area; CMR: Cardiovascular magnetic resonance; EDLV: End diastolic left ventricular volume; ESLV: End systolic left ventricular volume; ETA: Elongation of the transverse arch; FA: Flip angle; FOV: Field of view; GLM: Generalized linear model; ICD: Implanted cardioverter defibrillator; LV: Left ventricle/ ventricular; LVEF: Left ventricular ejection fraction; LVSV: Left ventricular stroke volume; MR: Magnetic resonance; MRA: Magnetic resonance angiography; PW: Pulse wave velocity; SD: Standard deviation; ST: Slice thickness; TA: Thoracic aorta; TAV: Tricuspid aortic valve; TE: Echo time; TR: Repetition time; TS: Turner syndrome; TWIST: Time-resolved angiography with stochastic trajectories; VENC: Velocity ENCoding

\section{Acknowledgements}

The authors wish to thank the Ghent University Hospital's Turner Clinic. The authors wish to thank Ir. P. Vandemaele for his technical support of this work.

The authors wish to thank Dr. C. Monten for her interest and feedback on Fig. 4.

\section{Funding}

Daniel Devos is recipient of a KOF clinical fellow ship nr AB/SDS/799/2008/ hdp from the University Hospital Ghent.

Danilo Babin is recipient of IWT (Spin-off) Innovation Mandate 130865.

None of the authors have relationships with industry to disclose, nor any conflict of interest relevant to the contents of this paper.

\section{Availability of supporting data}

The dataset(s) supporting the conclusions of this article is(are) included within the article (and its additional file(s)).

\section{Authors' contributions}

DGHD set up the study, scanned all patients and controls, performed image postprocessing and statisctial analysis, and drafted the manuscript. KDG helped with patient recruitment and manuscript revision. DB provided essential help in image postprocessing and manuscript revision. LD aided in patient recruitment, study design and manuscript revision. YT guided study design and revised the manuscript. JJW participated in study design and postprocessing, LVB provided essential help in recruitment of control subjects and study design, PS aided with image postprocessing tools and manuscript revision, EA participated in coordination of the study. JDS revised the manuscript. ER designed the statistical analyses and revised the manuscript. All authors read and approved the final manuscript.

\section{Authors' information}

Not applicable.

\section{Competing interests}

Daniel GH Devos: recipient of a KOF clinical fellow ship nr AB/SDS/799/2008/ hdp from the University Hospital Ghent.

Katya E De Groote: no competing interest to disclose.

Danilo Babin: recipient of IWT (Spin-off) Innovation Mandate 130865.

Laurent Demulier: no competing interest to disclose.

Yves Taeymans: no competing interest to disclose.

Jos JM Westenberg: no competing interest to disclose.

Luc Van Bortel: no competing interest to disclose.

Patrick Segers: no competing interest to disclose.

Eric Achten: no competing interest to disclose.

Jean De Schepper: no competing interest to disclose.

Ernst Rietzschel: no competing interest to disclose.

\section{Consent for publication}

Not applicable.

\section{Ethics approval and consent to participate}

This study was approved by the institutional ethical review board of the Ghent University Hospital (reference number: B67020084770). Written informed consent was obtained from all patients and control subjects.

\section{Author details}

'Department of Radiology, MRI (-1K12), Ghent University Hospital, De Pintelaan 185, B-9000 Gent, Belgium. ²Pediatric Cardiology, Department of Pediatrics and Turner Clinic, Ghent University Hospital, De Pintelaan 185, B-9000 Gent, Belgium. ${ }^{3}$ Telecommunications and Information Processing, TELIN-IPI-iMinds, Faculty of Engineering and Architecture, Ghent University, Sint-Pietersnieuwstraat 41, 9000 Ghent, Belgium. ${ }^{4}$ Department of Cardiology, Ghent University Hospital, De Pintelaan 185, B-9000 Gent, Belgium. ${ }^{5}$ Department of Radiology, Leiden University Medical Center, Albinusdreef 2, 2333 ZA Leiden, The Netherlands. ${ }^{6}$ Heymans Institute of Pharmacology, Ghent University Hospital, De Pintelaan 185, B-9000 Gent, Belgium. ${ }^{7}$ IBiTech-bioMMeda, Ghent University Hospital, De Pintelaan 185, B-9000 Gent, Belgium. ${ }^{8}$ Pediatric Endocrinology, Department of Pediatrics and Turner Clinic, Ghent University Hospital, De Pintelaan 185, B-9000 Gent, Belgium.

Received: 8 November 2016 Accepted: 20 January 2017

Published online: 13 February 2017

\section{References}

1. Stochholm K, Juul S, Juel K, Naeraa RW, Gravholt C. Prevalence, incidence, diagnostic delay, and mortality in turner syndrome. J Clin Endocrinol Metabolism. 2006:91(10):3897-902.

2. Sachdev V, Matura LA, Sidenko S, Ho VB, Arai AE, Rosing DR, et al. Aortic valve disease in turner syndrome. J Am Coll Cardiol. 2008;51(19):1904-9.

3. Gotzsche CO, Krag-Olsen B, Nielsen J, Sorensen KE, Kristensen BO. Prevalence of cardiovascular malformations and association with karyotypes in Turner's syndrome. Arch Dis Child. 1994;71:433-6.

4. Ho VB, Bakalov VK, Cooley M, Van PL, Hood MN, Burklow TR, et al. Major vascular anomalies in turner syndrome: prevalence and magnetic resonance angiographic features. Circulation. 2004;110(12):1694-700.

5. Mazzanti $L$, Prandstraller D, Fattori R, Lovato L, Cicognani A. Monitoring of congenital heart disease (CHD) and aortic dilatation in Turner syndrome: Italian experience. Int Congress Ser. 2006;1298(Complete):123-30.

6. Mazzanti L, Cacciari E. Congenital heart disease in patients with Turner's syndrome. Italian Study Group for Turner Syndrome (ISGTS). J Pediatr. 1998;5:688-92.

7. Mortensen $\mathrm{KH}$, Hjerrild BE, Andersen $\mathrm{NH}$, Sorensen $\mathrm{KE}$, Horlyck A, Edersen EM, et al. Abnormalities of the major intrathoracic arteries in Turner syndrome as revealed by magnetic resonance imaging. Cardiol Young. 2010;20(02):191-200

8. Prandstraller D, Mazzanti L, Picchio F, Magnani C, Bergamaschi R, Perri A, et al. Turner's syndrome: cardiologic profile according to the different chromosomal patterns and long-term clinical follow-up of 136 nonpreselected patients. Pediatr Cardiol. 1999;20(2):108-12.

9. Völkl T, Degenhardt K, Koch A, Simm D, Dörr H, Singer H. Cardiovascular anomalies in children and young adults with Ullrich-Turner syndrome the Erlangen experience. Clin Cardiol. 2005;28(2):88-92.

10. Dawson-Falk K, Wright A, Bakker B, Pitlick P, Wilson D, Rosenfeld R. Cardiovascular evaluation in Turner syndrome: utility of MR imaging. Australas Radiol. 1992;36(3):204-9.

11. Kim HK, Gottliebson W, Hor K, Backeljauw P, Gutmark-Little I, Salisbury SR, et al. Cardiovascular anomalies in turner syndrome: spectrum, prevalence, and cardiac MRI findings in a pediatric and young adult population. Am J Roentgenol. 2011:196(2):454-60.

12. Schoemaker MJ, Swerdlow AJ, Higgins CD, Wright AF, Jacobs PA. Mortality in women with turner syndrome in Great Britain: a national cohort study. J Clin Endocrinol Metabolism. 2008;93(12):4735-42.

13. Gravholt CH, Juul S, Naeraa RW, Hansen J. Morbidity in turner syndrome. J Clin Epidemiol. 1998:51(2):147-58.

14. Hiratzka LF, Bakris GL, Beckman JA, Bersin RM, Carr VF, Casey Jr DE, et al. 2010 ACCF/AHA/AATS/ACR/ASA/SCA/SCAI/SIR/STS/SVM guidelines for the diagnosis and management of patients with thoracic aortic disease. J Am Coll Cardiol. 2010:55(14):e27-e129.

15. Mortensen K, Erlandsen M, Andersen N, Gravholt C. Prediction of aortic dilation in Turner syndrome - enhancing the use of serial cardiovascular magnetic resonance. J Cardiovasc Magn Reson. 2013;15(1):47-58.

16. Segers P, De Backer J, Devos D, RABBEN SI, Gillebert T, Van Bortel L, et al. Aortic reflection coefficients and their association with global indexes of wave reflection in healthy controls and patients with Marfan's syndrome. Am J Physiol Heart Circ Physiol. 2006;290(6):2385. 
17. Blacher J, Guerin AP, Pannier B, Marchais SJ, Safar ME, London GM. Impact of aortic stiffness on survival in end-stage renal disease. Circulation. 1999; 99(18):2434-9.

18. Laurent S, Boutouyrie P, Asmar R, Gautier I, Laloux B, Guize L, et al. Aortic stiffness is an independent predictor of all-cause and cardiovascular mortality in hypertensive patients. Hypertension. 2001;37(5):1236-41.

19. Mattace-Raso FUS, van der Cammen TJM, Hofman A, van Popele NM, Bos $\mathrm{ML}$, Schalekamp MADH, et al. Arterial stiffness and risk of coronary heart disease and stroke: the Rotterdam study. Circulation. 2006;113(5):657-63.

20. Meaume S, Benetos A, Henry OF, Rudnichi A, Safar ME. Aortic pulse wave velocity predicts cardiovascular mortality in subjects $>70$ years of age. Arterioscler Thromb Vasc Biol. 2001;21(12):2046-50.

21. Sutton-Tyrrell K, Najjar SS, Boudreau RM, Venkitachalam L, Kupelian V, Simonsick EM, et al. Elevated aortic pulse wave velocity, a marker of arterial stiffness, predicts cardiovascular events in well-functioning older adults. Circulation. 2005;111(25):3384-90.

22. Ben-Shlomo Y, Spears M, Boustred C, May M, Anderson SG, Benjamin EJ, et al. Aortic pulse wave velocity improves cardiovascular event prediction: an individual participant meta-analysis of prospective-observational data from 17,635 subjects. J Am Coll Cardiol. 2014;63(7):636-46.

23. Meloni A, Zymeski H, Pepe A, Lombardi M, Wood JC. Robust estimation of pulse wave transit time using group delay. J Magn Reson Imaging. 2014; 39(3):550-8.

24. van Popele NM, Grobbee DE, Bots ML, Asmar R, Topouchian J, Reneman RS, et al. Association between arterial stiffness and atherosclerosis: the Rotterdam study. Stroke. 2001;32(2):454-60.

25. Vlachopoulos C, Aznaouridis K, Stefanadis C. Prediction of cardiovascular events and all-cause mortality with arterial stiffness: a systematic review and meta-analysis. J Am Coll Cardiol. 2010;55(13):1318-27.

26. Devos DGH, Rietzschel E, Heyse C, Vandemaele P, Van Bortel L, Babin $D$, et al. MR pulse wave velocity increases with age faster in the thoracic aorta than in the abdominal aorta. J Magn Reson Imaging. 2015;41(3):765-72

27. Mosteller RD. Simplified calculation of body-surface area. N Engl J Med. 1987;317(17):1098.

28. Matura $L A, H o \vee B$, Rosing DR, Bondy CA. Aortic dilatation and dissection in turner syndrome. Circulation. 2007;116(15):1663-70.

29. Grotenhuis HB, Westenberg JJ, Steendijk P, van der Geest RJ, Ottenkamp J, Bax $J$, et al. Validation and reproducibility of aortic pulse wave velocity as assessed with velocity-encoded MRI. J Magn Reson Imaging. 2009;30(3):521-6.

30. Mortensen KH, Hjerrild BE, Stochholm K, Andersen NH, Sorensen KE, Lundorf $E$, et al. Dilation of the ascending aorta in Turner syndrome - a prospective cardiovascular magnetic resonance study. J Cardiovasc Magn Reson. 2011;13:24-33.

31. Ostberg JE, Brookes JAS, McCarthy C, Halcox J, Conway GS. A comparison of echocardiography and magnetic resonance imaging in cardiovascular screening of adults with turner syndrome. J Clin Endocrinol Metabol. 2004;89(12):5966-71.

32. Olivieri LJ, Baba RY, Arai AE, Bandettini WP, Rosing DR, Bakalov V, et al. Spectrum of aortic valve abnormalities associated with aortic dilation across age groups in turner syndrome. Circ Cardiovasc Imaging. 2013;6:1018-23.

33. Rogers WJ, Hu YL, Coast D, Vido DA, Kramer CM, Pyeritz RE, et al. Ageassociated changes in regional aortic pulse wave velocity. J Am Coll Cardiol. 2001;38(4):1123-9.

34. Lawson SA, Urbina EM, Gutmark-Little I, Khoury PR, Gao Z, Backeljauw PF. Vasculopathy in the young turner syndrome population. J Clin Endocrinol Metabolism. 2014;99(10):E2039-45.

35. Baguet JP, Douchin S, Pierre H, Rossignol AM, Bost M, Mallion JM. Structural and functional abnormalities of large arteries in the Turner syndrome. Heart. 2005:91(11):1442-6.

36. De Groote K, Devos D, Van Herck K, Demulier L, Buysse W, De Schepper J, et al. Abnormal aortic arch morphology in Turner syndrome patients is a risk factor for hypertension. Heart Vessels. 2015;30(5):618-25.

37. Sybert V. Cardiovascular malformations and complications in Turner syndrome. Pediatrics. 1998;101(1):E11.

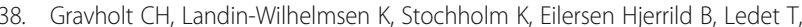
Born Djurhuus $C$, et al. Clinical and epidemiological description of aortic dissection in Turner's syndrome. Cardiol Young. 2006;16(05):430-6.

39. Meszaros I, Morocz J, Szlavi J, Schmidt J, Tornoci L, Nagy L, et al. Epidemiology and clinicopathology of aortic dissection: A population-based longitudinal study over 27 years. Chest. 2000;117(5):1271-8.
40. Carlson M, Silberbach M. Dissection of the aorta in Turner syndrome: two cases and review of 85 cases in the literature. J Med Genet. 2007:44(12):745-9.

41. Hagan PG, Nienaber CA, Isselbacher EM. The international registry of acute aortic dissection (irad): New insights into an old disease. JAMA. 2000;283(7): 897-903.

42. An HS, Baek JS, Kim GB, Lee YA, Song MK, Kwon BS et al. Impaired vascular function of the aorta in adolescents with turner syndrome. Pediatric Cardiol. 2016;1-7. https://dx.doi.org/10.1007/s00246-016-1478-4.

43. Bondy CA. Care of girls and women with Turner syndrome: A guideline of the Turner Syndrome Study Group. J Clin Endocrinol Metab. 2007;92:10-25.

44. Turtle EJ, Sule AA, Webb DJ, Bath LE. Aortic dissection in children and adolescents with Turner syndrome: risk factors and management recommendations. Arch Dis Child. 2015;100(7):662-6.

45. Mortensen KH, Hansen KW, Erlandsen M, Christiansen JS, Gravholt CH. Ambulatory arterial stiffness index in Turner syndrome: the impact of sex hormone replacement therapy. Horm Res. 2009;72:184-9.

46. Fielden SW, Fornwalt BK, Jerosch-Herold M, Eisner RL, Stillman AE, Oshinski JN. A new method for the determination of aortic pulse wave velocity using cross-correlation on 2D PCMR velocity data. J Magn Reson Imaging. 2008;27(6):1382-7.

47. Westenberg JJM, de Roos A, Grotenhuis HB, Steendijk P, Hendriksen D, van den Boogaard PJ, et al. Improved aortic pulse wave velocity assessment from multislice two-directional in-plane velocity-encoded magnetic resonance imaging. J Magn Reson Imaging. 2010;32(5):1086-94.

48. Mohiaddin RH, Firmin DN, Longmore DB. Age-related changes of human aortic flow wave velocity measured noninvasively by magnetic resonance imaging. J Appl Physiol. 1993;74(1):492.

49. Dorniak K, Heiberg E, Hellmann M, Rawicz-Zegrzda D, Wesierska M, Galaska $\mathrm{R}$, et al. Required temporal resolution for accurate thoracic aortic pulse wave velocity measurements by phase-contrast magnetic resonance imaging and comparison with clinical standard applanation tonometry. BMC Cardiovasc Disord. 2016;16(1):110.

50. Bargiotas I, Mousseaux E, Yu WC, Venkatesh BA, Bollache E, de Cesare A et al. Estimation of aortic pulse wave transit time in cardiovascular magnetic resonance using complex wavelet cross-spectrum analysis. J Cardiovasc Magn Reson. 2015;17(1):65

51. Bell V, Mitchell WA, Sigurdsson S, Westenberg JJM, Gotal JD, Torjesen AA, et al. Longitudinal and circumferential strain of the proximal aorta. J Am Heart Assoc. 2014:3(6):e001536.

\section{Submit your next manuscript to BioMed Central and we will help you at every step:}

- We accept pre-submission inquiries

- Our selector tool helps you to find the most relevant journal

- We provide round the clock customer support

- Convenient online submission

- Thorough peer review

- Inclusion in PubMed and all major indexing services

- Maximum visibility for your research

Submit your manuscript at www.biomedcentral.com/submit
) Biomed Central 